\title{
EEG Results are Rarely the Same if Repeated within Six Months in Childhood Epilepsy
}

\author{
Peter Camfield, Kevin Gordon, Carol Camfield, John Tibbles, Joseph Dooley and \\ Bruce Smith
}

\begin{abstract}
Objective: To assess the reliability of interictal spike discharge in routine electroencephalography (EEG) testing in children. Method: EEG results of all children diagnosed in Nova Scotia with epilepsy onset between 1977-85 (excluding myoclonic, akinetic-atonic and absence) were reviewed. The results of the EEG at time of diagnosis (EEG1) were compared with those of a second EEG (EEG2) within 6 months. Results: Of 504 children with epilepsy, 159 had both EEGI and EEG2. EEG2 was more likely ordered if EEG1 was normal or showed focal slowing but less likely if EEG I contained sleep $(p<0.05)$. EEG1 and EEG2 were both normal in 23\%. If EEG1 was abnormal, there was a $40-70 \%$ discordance for the type of abnormality on EEG2. Abnormalities were present on both EEG1 and EEG2 in 67 cases. Of the 42/67 with major focal abnormalities on EEG1, 7 had only generalized spike wave on EEG2. Of the 17/67 with only generalized spike wave on EEG1, 7 showed only major focal abnormalities on EEG2. Statistical testing showed low Kappa scores indicating low reliability. Conclusions: The interictal EEG in childhood epilepsy appears to be an unstable test. A repeat EEG within 6 months of a first EEG may yield different and sometimes conflicting information.
\end{abstract}

\begin{abstract}
RÉSUMÉ: Le tracé EEG est rarement identique au tracé initial si on le répète en dedans de six mois chez l'enfant épileptique. Objectif: Le but de l'étude était d'évaluer la fiabilité des décharges de pointes interictales dans les EEGs de routine chez l'enfant. Méthode: Nous avons révisé les EEGs de tous les enfants chez qui on a posé un diagnostic initial d'épilepsie entre 1977 et 1985 (excluant l'épilepsie myoclonique, akinétique-atonique et les absences). Le résultat de l'EEG initial (EEG1) a été comparé à celui du second EEG fait dans les six mois du premier (EEG2). Résultats: Parmi les 504 enfants épileptiques, 159 ont subi les deux examens, l'EEG! et l'EEG2. L'enfant était plus susceptible d'avoir subi l'EEG2 si l'EEGl était normal ou montrait un ralentissement focal et il était moins probable qu'il l'ait subi si l'EEGI incluait du sommeil $(\mathrm{p}<0.05)$. Les deux EEGs étaient normaux chez 23\% des enfants. Si l'EEGl était anormal, il y avait une discordance de 40 à $70 \%$ quant au type d'anomalie présente à l'EE2. Les deux EEGs étaient anormaux chez 67 cas. Parmi les $42 / 67$ cas dont l'EEG présentait des anomalies focales majeures, 7 avaient seulement des complexes pointe-onde généralisés à l'EEG2. Parmi les 17/67 cas dont l'EEG présentait des complexes pointe-onde à l'EEGI, 7 présentaient seulement des anomalies focales majeures à l'EEG2. L'analyse statistique a montré un score de Kappa bas indiquant un faible degré de fiabilité. Conclusions: L'EEG interictal dans l'épilepsie de l'enfant semble être une épreuve instable. Un EEG de contrôle dans les six mois du premier peut fournir une information différente et parfois discordante.
\end{abstract}

Can. J. Neurol. Sci. 1995; 22: 297-300

Electroencephalography (EEG) remains the principal investigation for children with epilepsy. This technique was introduced 60 years ago and like many older technologies has not been subjected to strict reliability assessments. The classification of a child's epilepsy and possibly investigation and treatment often depend on interictal EEG results. Therefore, it is important to know if EEG results close to the time of diagnosis of epilepsy are consistent. If they are not, they may be misleading.

The goal of this study was to document the stability of EEG findings in children with epilepsy within 6 months of diagnosis. This is a unique study of EEG in children, because it involves an entire regional population.

\section{METHOD}

\section{Case Finding: Inclusion, Exclusion Criteria}

Our previous studies have indicated that all children in Nova Scotia who present to the medical care system with a clinical diagnosis of epilepsy will have an EEG requested.' We interpret

From the Department of Pediatrics and Mathematics, Dalhousie University and the IWK Children's Hospital, Halifax, Nova Scotia.

RECEIVED DECEMBER 12, 1994. ACCEPTED IN FINAL FORM MAY 16, 1995

Reprint requests to: Dr. Peter Camfield, IWK Children's Hospital, Box 3070, Halifax, Nova Scotia, Canada B3J 3G9 
all of the pediatric EEGs for the province. Therefore, pediatric EEG requests plus chart review and direct patient contact provided a case finding method to identify all children who developed epilepsy in Nova Scotia between 1977 and 1985. Children were included if they had 2 or more unprovoked afebrile seizures, and the first 2 seizures occurred within the study period. Patients were between 1 month and 16 years of age at the time of the second seizure and were residents of Nova Scotia for these first two seizures. They were followed up in 1989-90.

Children with akinetic, atonic, myoclonic and absence seizures were excluded because the principal goal of the study was to document the prognosis of epilepsy in children with other seizure types. ${ }^{2}$ Children were also excluded if there were acute provoking factors for their seizures (for example - fever, head injury, hypoglycemia), progressive neurologic disease or brain tumour.

\section{Electroencephalography}

The EEG at the time of diagnosis was defined as EEG1. By definition, all children with epilepsy had a first EEG at the time of diagnosis since this formed the basis of the case finding method. Based on clinical practice decisions by the treating physician, some children had a second EEG within 6 months of the first. This was defined as EEG2.

EEG results were coded from reports by a registered EEG technician. Cluster analysis of EEG findings suggested 8 categories - normal, diffuse background abnormality more severe than mild (i.e., increased theta and delta or poorly organized occipital dominant activity), focal slowing without spikes (slowing = increased theta or delta), unifocal spikes, focal spikes plus focal slowing, multifocal spikes, focal spikes with secondary generalization and generalized spike and wave. The findings for each EEG were then assigned to one of these categories. The length of time between the last seizure and EEG recording was not included in this analysis.

The effect of antiepileptic medication on the EEG results could not be analyzed because the exact timing of the EEG relative to the beginning of treatment was not always available.

EEGs were recorded in 2 laboratories (IWK Children's Hospital, Halifax and St. Rita's Hospital, Sydney, Nova Scotia). Routine sedation was not used and natural sleep was recorded in $50 \%$. The 10-20 electrode system was used with a routine recording time of approximately 30 minutes. Photic stimulation was nearly always carried out and hyperventilation for $3 \mathrm{~min}-$ utes was recorded in all who were capable of cooperation.

\section{Statistical Methods}

Categories of EEG abnormalities were determined from a cluster analysis of EEG results. This allowed consolidation of EEG results into 8 categories (see Table 1). Results of EEG1 and EEG2 were compared using the Kappa statistic. ${ }^{3}$ Chisquared, Wilcoxon and Fisher exact tests were used for other group comparisons.

\section{RESULTS}

Five hundred and four children developed epilepsy as defined by the study inclusion-exclusion criteria. There were complete clinical and EEG data for all coded variables for 438 children.
Table 1: Summary of overall EEG Results.

\begin{tabular}{lrr}
\hline & EEG1 & EEG2 \\
\hline Normal & 68 & 60 \\
Generalized background abnormality & 13 & 6 \\
Focal slow, no spikes & 10 & 5 \\
Unifocal spikes & 17 & 22 \\
Unifocal spikes with focal slow & 6 & 4 \\
Multifocal spikes & 19 & 25 \\
Focal spikes with secondary generalization & 7 & 9 \\
Generalized spike and wave & $\underline{19}$ & $\underline{28}$ \\
Total & 159 & 159 \\
\hline
\end{tabular}

The 159 who had both EEGI and EEG2 form the basis of this report.

Clinical characteristics of those who did not have a second EEG within 6 months of the first were compared with those who had both EEG1 and EEG2. There was no statistical difference in age of onset, seizure type, seizure cause, presence of neurologic abnormality or mental retardation, number of seizures in the first 6 months of treatment or number of antiepileptic medications prescribed during the first 6 months of treatment. The greater the number of seizures prior to treatment, the greater likelihood of EEG2 ( $p=0.03$, Wilcoxon rank sums). Children with a preceding febrile seizure were $65 \%$ less likely to have EEG2 (9/159 vs. 55/279 p $<0.001$ chi-squared).

Three features of EEG1 were statistically significant in predicting the recording of EEG2. If EEG1 was normal the chance of EEG2 increased by $30 \%$ (54/159 vs. $70 / 279 p=0.05$ chisquare). On the other hand, if the child slept during EEGl the likehood of EEG2 decreased by 23\% (70/159 vs. $152 / 279 \mathrm{p} \mathrm{=}$ 0.032 chi-squared). If there was focal slowing on EEGl, the chance of EEG2 was increased by $44 \%$ (41/159 vs. $44 / 279 p=$ 0.01 ). Other types of abnormalities on EEG1 were not significantly associated with EEG2. Sleep did not have a statistically significant effect on the rate of any of the categories of abnormality.

The distribution of abnormalities was very similiar on EEG1 and EEG2 (Table 1). For individual patients, however, the results of the two EEGs often differed (Table 2). If EEG results were simply categorized as normal or abnormal then overall, the results of the two EEGs were concordant in $103(65 \%)$ patients but shifted between normal and abnormal in $56(35 \%)$. The Kappa statistic for this simple division of results is 0.27 (95\% confidence interval $0.12-0.42$ ) indicating poor reliability.

All categories of EEG results showed similar degrees of discordance. Table 3 shows the results of EEG2 for each category of result in EEG1. Overall, 68 (43\%) EEG2 results were the same as EEG1. For example, of 68 children with a normal EEG1, only $36(53 \%)$ had a normal result on EEG2. Only six of seventeen $(35 \%)$ with unifocal spikes on EEGl showed unifocal spikes on EEG2.

We examined in detail the 67 patients with abnormalities on both EEG1 and EEG2 (Table 4). For this group, formal statistical testing for consistency of findings between EEG1 and EEG2 was again very low (Kappa $=0.36,95 \%$ confidence interval $0.21-0.50$ ). For clarity, all focal abnormalities (unifocal spike, unifocal spike plus focal slowing, multifocal spikes and focal 
Table 2: Relationship of results of EEG1 and EEG2.

\begin{tabular}{lll}
\hline Both Normal & 36 & $(23 \%)$ \\
EEG1 abnormal, EEG2 abnormal & 67 & $(42 \%)$ \\
EEG1 abnormal, EEG2 normal & 24 & $(15 \%)$ \\
EEG1 normal, EEG2 abnormal & 32 & $(20 \%)$ \\
\hline
\end{tabular}

Kappa $=0.27(95 \%$ confidence interval $0.12-0.42)$

Table 3: Findings on EEGI that remained the same on EEG2.

\begin{tabular}{lccc}
\hline & EEG1 & EEG2 & $\boldsymbol{\%}^{*}$ \\
\hline Normal & 68 & 36 & 53 \\
Generalized background abnormality & 13 & 3 & 23 \\
Focal slow, no spikes & 10 & 2 & 20 \\
Unifocal spikes & 17 & 6 & 35 \\
Unifocal spikes with focal slow & 6 & 2 & 33 \\
Multifocal spikes & 19 & 7 & 37 \\
Focal spikes with secondary generalization & 7 & 2 & 29 \\
Generalized spike and wave & 19 & 10 & 52 \\
Total & 159 & 159 & \\
\hline
\end{tabular}

* This column shows the percent of patients with a given result on EEG1 who had the same result on EEG2.

Table 4: Comparison on EEG1 and EEG2 results when both are abnormal.

\section{EEG1}

\begin{tabular}{lclr}
\hline Generalized spike wave & 17 & generalized spike-wave & 10 \\
& & focal spikes plus sec gen & 2 \\
& multifocal spikes & 3 \\
& focal spikes & 2
\end{tabular}

Major focal abnormality $44 \quad$ major focal abnormality 35 generalized spike-wave 7 generalized background 2

\begin{tabular}{llll} 
Generalized background & 6 & generalized background & 3 \\
& & major focal abnormality & 3 \\
\hline
\end{tabular}

Major focal abnormality $=$ focal delta, focal spikes, focal spikes plus focal delta, multifocal spikes

sec gen $=$ secondary generalization

generalized background = generalized background abnormality of moderate or severe degree

slowing) were combined and shown in Table 4 as "major focal" abnormality. From this table it can be seen that of the 17 with generalized spike and wave on EEG1, $7(41 \%)$ showed a major focal abnormality on EEG2. Of the 42 with a major focal abnormality EEGI, 7 (16\%) showed generalized spike and wave discharge on EEG2 ( $p=0.05$ Fisher exact, 2-tailed).

\section{Discussion}

Our results suggest that EEG findings in children with newly diagnosed epilepsy (excluding myoclonus, absence and akineticatonic seizures) vary in important ways when they are repeated within six months. The clinical implications of this variability depend on how the results change. An initial normal EEG that becomes abnormal may be the result of a "sampling" error, since EEG abnormalities may not be present all the time and routine EEGs are often recorded for less than one hour. An initial abnormal EEG which becomes normal may be reassuring and reflect the effect of antiepileptic medication. Real concern about varying EEG patterns occurs when the type of abnormality changes dramatically from the first to second EEG. In our experience, $41 \%$ of patients with generalized spike wave on the first EEG showed major focal abnormalities on the next EEG. Focal abnormalities were significantly less likely to become generalized; however, a substantial proportion (16\%) of those with major focal abnormalities showed only generalized spike wave on repeat. Which record should be regarded as the most important for investigation and treatment?

Our study is population-based and EEG requests were the result of clinical judgment, not a rigid experimental protocol. ${ }^{2}$ Therefore, our results might be reasonably extrapolated to a clinical practice setting where the effects of medication treatment or length of time since the last seizure have an uncertain effect on the EEG. If all patients had a repeat EEG, then it is possible that the consistency of results might have been better (or worse!). In clinical practice there would be little justification for a repeat EEG on every patient.

It is not possible to determine why some children had a repeat EEG and others did not. None of the results of EEG 1 were very powerful predictors of findings on EEG2. In addition, there was no difference in age at first seizure, seizure type, cause, or accompanying neurologic problems. Seizure control was the same between the two groups during the first 6 months of treatment. We did request EEG2 more often if EEG1 was either normal, without sleep or demonstrated focal slowing. These tendencies may be standard practice and reflect a desire to define the EEG correlate of a child's seizure disorder or exclude a progressive focal lesion. Preceding febrile seizures decreased the chance of EEG2 while the chance was increased with greater numbers of pretreatment seizures. These features are of uncertain significance and it is likely that there were other ill-defined biases in selecting some children for EEG2, such as family or physician anxiety. A more rigorous systematic study with repeat EEGs for all children with newly diagnosed epilepsy would be of interest to show the overall consistency of EEG results, not just in a practice setting.

All the EEGs during the study period were interpreted by two experienced pediatric electroencephalographers who routinely discussed records with uncertain findings. The categories of EEG results were fairly striking. Although we believe that interobserver reliability would have been high, no formal test of this assumption was carried out.

Each category of EEG results contains relatively small numbers of patients; therefore, the consistency of localization of focal spikes and the regularity of generalized spike wave could not be analyzed. Studies of the localization of focal spikes in children with persistent EEG spikes have suggested remarkable migration from one area to another over time. ${ }^{4}$ Patients with absence, myoclonic and akinetic seizures were excluded from our study and therefore our results should not be extended to these seizure types.

We are unaware of any comparable study. It is known that a proportion of children with epilepsy will show "improvement" or "deterioration" in their EEG findings when the EEG at diagnosis is compared to the EEG after several years seizure free..$^{5.6}$ 
Many years after diagnosis patients with rolandic spikes may show generalized spike and wave discharge. ${ }^{7}$ Gibbs and Gibbs described the anterior migration of spikes in children. ${ }^{8}$ These types of studies suggest that with maturation, the epileptic tendency may change, at least as reflected in the interictal EEG. These studies do not, however, address the validity of the EEG in the early stages of the diagnosis of epilepsy.

It has been suggested that the more EEGs that are performed on a patient, the greater the chance of finding interictal spikes. One study suggested that only $50 \%$ of patients with epilepsy show spikes on an initial EEG (43\% in the present series). ${ }^{9}$ The finding of spikes is highly correlated with epilepsy although a small percent of the normal population will show similar discharge. ${ }^{10}$ Therefore, the clinician may be tempted to order repeated EEGs when the diagnosis of epilepsy is in doubt. This may be justifiable; however, when the diagnosis is clear cut, routine repetition of EEG will likely give varying results that, in our opinion, would be of little clinical value. Based on the inconsistency of EEG results in children with epilepsy, we would urge great caution in treatment decisions based on EEG alone.

\section{ACKNOWLEDGEMENT}

Our thanks to Kathy Chang RET for abstracting the EEG results.

\section{REFERENCES}

1. Camfield PR, Camfield CS, Dooley JM, et al. Epilepsy after a first unprovoked seizure in childhood. Neurology 1985; 35: 16571660.

2. Camfield CS, Camfield PR, Gordon KE, Dooley JM, Smith BS. Predicting the outcome of childhood epilepsy - a population based study yielding a simple scoring system. J Pediatr 1993; 122: 861-868.

3. Streiner DL, Norman GF. Health Measurement Scales - a Practical Guide to their Development and Use. Oxford: University Press 1989: 79-96.

4. Trojaborg W. Changes in spike foci in children. In: Kelleway P, Petersen I, eds. Clinical Electroencephalography of Children. New York: Grune \& Stratton, 1968; 213-226.

5. Emerson R, D'Souza BJ, Vining EP, et al. Stopping medication in children with epilepsy: predictors of outcome. $\mathrm{N}$ Engl J Med 1981; 304: 1125-1129.

6. Shinnar S, Vining EP, Mellits ED, et al. Discontinuing antiepileptic medication in children with epilepsy after two years without seizures: a prospective study. N Engl J Med 1985; 313: 976-980.

7. Gibbs EL, Gibbs FA. Disappearance and migration of epileptic foci in childhood. Am J Dis Child 1954; 88: 596-603.

8. Bray PF, Wiser WC. The relation of focal to diffuse epileptiform EEG discharges in genetic epilepsy. Arch Neurol 1965; 13: 223-237.

9. Ajmone Marsan C, Zivin LS. Factors related to the occurrence of typical paroxsymal abnormalities in the EEG records of epileptic patients. Epilepsia 1970; 11:361-381.

10. Petersen O, Eeg-Olofsson O. Paroxsymal activity in EEG of normal children. In: Kelleway $\mathrm{P}$, Petersen I, eds. Clinical Electroencephalography of Children. New York: Grune \& Stratton, 1968; 167-188. 